\section{Effect of Air Currents, Light, Humidity and Temperature on Slugs}

IN view of the communication by Kalmus ${ }^{1}$, it is of interest to record a brief summary of results obtained during an attempt to determine the causes of activity in slugs. The results will be considered under four headings, namely, responses to (1) air currents, (2) light, (3) humidity, and (4) temperature.

(1) Air Currents. A gentle draught of air (just perceptible to the observer's cheek) was played across the path of slugs (Agriolimax reticulatus and Limax maximus) just in front of the animals. The slugs turned away, going through the following movements. The tentacles were withdrawn, the head moved to right or left and the tentacles extended again. This process was repeated until the tentacles eventually remained extended and the animal moved away from the draught, presumably because the tentacles were no longer stimulated. Air played on the tail or body of the slug increased the speed of locomotion or, if the animal was at rest, induced activity. The same result was obtained using saturated air, showing that the effect was not due to the temperature drop (see below) caused by the evaporation of water which occurs when dry air is used. Air currents thus have a dual effect : $(a)$ stimulation of the tentacles affecting the direction of locomotion, and $(b)$ stimulation of the body or tail affecting the occurrence or speed of locomotion.

The above effects were readily demonstrated on a specimen of Limax maximus moving over a glass plate. Observation of the sole showed that stimulation of the tentacles by air currents involved immediate inhibition of the locomotory waves, while stimulation of the body or tail initiated waves or increased their speed. This inhibition of the locomotory waves by anterior stimulation is in accord with experiments in which a posterior half of a slug, completely severed from the head end, produced locomotory waves without ceasing for two hours after isolation.

(2) Light. In some instances slugs (A. reticulatus) kept at constant temperature in the dark showed increased activity when illuminated by electric light, though the increase was never as marked as in the temperature responses described below. The effect was short-lived, adaptation occurring quickly. In the final experiments using 72 animals at a time and noting activity at 15-minute intervals (instead of 5 -minute as in previous experiments) no effect was obtained, possibly because adaptation occurred within 15 minutes. (In considering these experiments it is necessary to remember that a light was used for taking the readings in the dark, and the animals were thus illuminated for occasional short periods (1-2 minutes). The animals showed a typical avoiding reaction at the boundaries of well-defined regions of bright light. The boundary was, however, traversed if this was the only way in which the slug could avoid facing into a draught (see above).

(3) Humidity. At room temperature $\left(16-18^{\circ} \mathrm{C}\right.$.) slugs ( $A$. reticulatus) were found to be no more active at high than at low humidities. No orthokinesis comparable with that described by Gunn ${ }^{2}$ in the woodlouse or by Pielou and Gunn ${ }^{3}$ in the mealworm was observed. Slightly greater activity was obtained at low humidity. This may be explained as a response to the fall in temperature (see below) which occurs when a damp object is introduced into a dry atmosphere.
Humidity might affect the animals indirectly by altering their water content. Experiments on $A$. reticulatus and $L$. maximus showed that when loss of water by evaporation and mucus production exceeded a certain minimum value, the distance moved after the animal was transferred to an arena was reduced. The nature of the normal habitat of slugs makes it unlikely that such a reduction in water content would occur owing to evaporation \&lone, particularly as slugs can be shown to absorb water readily from damp objects with which they are in contact. Loss of water by mucus production may affect the occurrence of activity, and since mucus is produced during locomotion, may also limit its duration. Howes and Wells ${ }^{4}$ observed weight fluctuations due to water content in Arion ater living under laboratory conditions but made no correlation with activity.

(4) Temperature. Slugs (A. reticulatus) respond readily to temperature changes. No correlation was observed between degree of activity and temperature when the latter was kept constant. Activity was, however, invariably stimulated by rising temperature above a critical value of about $20^{\circ} \mathrm{C}$. Below this value the effect was reversed and activity stimulated by falling temperature. (In both cases the rate of rise or fall was about $1^{\circ} \mathrm{C}$. in 10 minutes.) If the temperature was kept constant at any value, the activity fell to a low level. Some evidence has been obtained that temperature changes towards the critical value of $20^{\circ} \mathrm{C}$., that is, in the reverse direction to those above, reduce activity below the level observed at constant temperature.

The results of these and related experiments will be published in detail elsewhere.

Zoological Laboratory,

Cambridge.

Dec. 8.

${ }^{1}$ Kalmus, NATURE, 150, 524 (1942).

Gunn, J. Exper. Biol., 14, 178 (1937).

- Pielou and Gunn, J. Exper. Biol., 17, 307 (1940).

- Howes and Wells, J. Exper. Biol., 11, 326 (1934).

\section{Discoveries by Accident}

IT is not derogatory of a discoverer to say that his discovery arose from an accident; for the power to use accidents, events the occurrence of which was not intended, is the mark of one form of scientific genius. Probably all experimenters are presented with about the same number of accidents which, if they had had the wit, would have led them to important discoveries ; but most of us fail to appreciate their significance until the discovery has been made by somebody else; we may then fail to remember them or forget them to save our self-respect. I know that I had at least three such accidents that would certainly have led Röntgen to discoveries, if not as important as X-rays, at least of considerable technical and scientific interest. Two of them I missed entirely, and the third I used very imperfectly.

Doubtless there is another form of scientific genius that proceeds from triumph to triumph according to an ordered plan; but it is seldom certain that the progress was really as orderly as it appears when the results are presented. Even if this form must be reckoned the higher, science would never have reached its present position without the other.

21 Carlton Hill, N.W.8. Norman R. Campbell.

Dec. 18. 